\title{
PHYSICAL OR THEOLOGICAL APPROACH TO INVESTIGATE THE SHROUD IMAGE FORMATION BY UV RADIATION?
}

\author{
Prof. PhD. Giovanni FAZIO, \\ Università di Messina, Dipartimento MIFT \\ Viale Ferdinando Stagno d'Alcontres, I-98166 Messina \\ ITALY \\ E-mail: gfazio@unime.it
}

\begin{abstract}
In this article, we ask ourselves if it is possible that Corona Discharge or Vacuum UV radiation may have been the tools to produce the Shroud body image. We are convinced that both are not appropriate mechanisms. In fact, the start of these processes is based on inconsistent hypotheses for the natural sciences, although all that follows is rational, reasonable and acceptable. However, the big initial mole remains. The complexity of this situation is such that it seems to be in a world in part Transcendent and in part Immanent. Therefore, independently from the possible results that in a next future could be obtained, due to identified photochemical processes, the Scientific Method cannot accept both the hypotheses and, consequently, the experiments. The same is also for the Theological approach which discards both proposals.
\end{abstract}

Keywords: Shroud of Turin; Body Image formation; Corona Discharge; VUV radiation; Stochastic process;

\section{INTRODUCTION}

The image that appears on the Linen of Turin is, obviously, the synthesis of an interaction between the corpse wrapped in the burial sheet and the fabric itself. Therefore, to obtain such a result there was a transfer of energy from the body to the above linen that wrapped it. Therefore, it is important for the scientists to find a source inside the sepulcher.

Many have been the attempts inspired by the different scientific areas, as physics and chemistry. Evidently, it is very difficulty to extract the mechanism of the Shroud body image formation. In fact, none have had a full success. So, for some decades, the research on the Shroud of Turin has been and is focused on the action of the radiations.

The motivations of this tendency are:

1) The difficulty to find a reasonable solution with others non-radiative mechanisms.

2) The fact that the ionizing radiation has, generally, as result the oxidation of the flax and, therefore, its yellowing at the macroscopic level.

3) The description of the Transfiguration of the Nazarene, as it is described in the Synoptic Gospels (New American Bible, 2010).

4) The fashion of the emission of one radiation by the corpse wrapped in a funerary linen.

When the suitable mechanism will be found, only one among the possible hypotheses (which are that of false, that of a transcendental event and that of a natural event) will be satisfied. In reality, we have not three mechanisms in competition, but three family of 
mechanisms in competition. This occurs because each of the three hypotheses appears with various processes.

These four Items make us think that these hypotheses don't lie in the world of the rational happenings. In the Immanent, for the scholars of the natural sciences, an acceptable solution could already have been found. Here, we are in the transcendental world where the scientific knowledge with his instruments is neither sufficient nor appropriate to study these events. In these cases, the natural sciences have only the possibility to affirm that such an event is happened without to be capable of describing how. In fact, for such an event, the description step by step is impossible (Fazio, 2020).

Nowadays, some scientists start their articles with incomprehensible hypotheses. We, in literature, have seen papers that describe the possibility of the protons (Rinaudo, 1993 and 1994; Antonacci, 2000 and 2012) and of the ultraviolet radiation (Fanti, 2010; Di Lazzaro et al., 2012) to reproduce in a linen an image as the one present on the Shroud of Turin (Mottern et al., 1980; Gilbert and Gilbert, 1980; Pellicori and Evans, 1981; Heller and Adler, 1981; Miller and Pellicori, 1981; Schwalbe and Rogers, 1982; Jumper et al., 1984). So, after reading the above articles on this topic, we have decided to investigate on these processes starting with hypotheses in conflict with the natural sciences.

However, the sole source of energy available in an ancient tomb of the first century it is the thermal one. The energy is naturally emitted due to the thermal state of the corpse which is warmer than the burial linen. Anyway, in the history of the natural sciences, no one has never seen a corpse that emits radiations. Thus, with this state of affairs, we have decided to investigate on the use of ultraviolet radiation as tool to obtain a copy of the above image.

\section{ANALYSIS AND DISCUSSIONS}

The interaction between radiant energy and organic substances develops with the absorption of the radiation energy by the organic substance (for example: linen) followed by the dissipation of energy through heat, emission of radiation (fluorescence or phosphorescence), transfer of the energy to another molecular entity or direct bond breaking (Feller, 1994).

Intellectual honesty wants us to inform shortly the readers that, unlike other scientists, we have considered a transfer of thermal energy because this last one is the sole present in an ancient sepulcher. The source of this energy is the corpse wrapped in the burial sheet. This hypothesis is not in contrast with the physics laws. We underline that a corpse can exceed even 40 degrees Celsius, sufficient to transfer a little quantity of energy to the linen that triggers a stochastic process. This is a mechanism that does not yield effects only when the transferred energy is zero (Fazio and Mandaglio, 2011 and 2012; Fazio et al., 2015 and 2019). In other words, to have such a process, the transferred energy must be in a little quantity.

This mechanism furnishes a latent result (after years or decades) and an uneven superficial distribution of the yellowed fibrils, the ones that yield the body image. In fact, the results of this process guarantee a yellowed fibrils distribution with an image intensity that, versus the body-sheet distance, is represented by a linear regression (Jackson et al., 1982 and 1984).

The scientific literature shows a great variety of radiative experiments proposing hypotheses that do not agree with natural laws. Also the two searches, which we investigate in this paper, have the above characteristic. 
They are focused on the UV radiation-linen interaction (Fanti, 2010; Di Lazzaro et al., 2012). The first one on an intense Corona Discharge with plasma formation, heat and UV radiation; the second one on the use of a pulsed excimer laser (ArF) that yields UV radiation in the far ultraviolet with $\lambda=193 \mathrm{~nm}$, that penetrates for about $200 \mathrm{~nm}$.

Using a vacuum ultraviolet radiation with the above $\lambda$ value no color appears, but the natural or artificial aging showed a Shroud-like coloring. So, they have obtained a latent coloring. Moreover, they claim that the most important result is to have identified photochemical processes capable of explaining the surface coloring and possibly to understand in details as the Shroud image has been produced (Di Lazzaro et al., 2012).

The other line of research is focused on Corona Discharge (Fanti, 2010). Here, it is necessary to have an electrical conductor immersed in a fluid dielectric (generally air). When, between the two electrodes, the voltage is very high and the current circulates, the electrons ionize the dielectric with production of ions and electrons pair, before absent. So, in this process, we will have positive ions and electrons moving towards their electrodes generating plasma, and also heath with UV radiation are produced. In other words, when the electrical field inside a conductor exceeds the value of the dielectric rigidity of the fluid $\left(3 \mathrm{kV} \cdot \mathrm{mm}^{-1}\right.$ for the dry air), Corona Discharge arises. This effect for his supporters represents the true architecture of the Shroud body image formation.

However, both cases display the same modus operandi: at first, there is a proposal that cannot be accepted by the natural sciences that later it is followed by reasonable logical operations, in line with the above sciences. In any case, the problems are already present at the beginning. In fact, it is not possible for anyone to accept the idea that a corpse can do what is described in their articles (Fanti, 2010; Di Lazzaro et al., 2012). Moreover, these radiations have not the possibility to color the fibrils that must turn yellow, with respecting to the ones that must maintain the background color.

It is evident that in the two experiments the Scientific Method (Rogers and Arnoldi, 2002) has not been respected from the scientists. Therefore, we believe that the problems related to the start of the two experiments must be of theological pertinence. In fact, in the initial part that is decisive, both show a transcendental event and the natural sciences, as already affirmed, are not adequate to investigate such phenomena.

At this point, it is much difficult to accept these two models even if one of these affirms to have obtained a linen fabrics with Shroud-like coloring (Di Lazzaro et al., 2012). We believe in this result but, in our opinion, it is different to obtain on the same linen a body image with all the known characteristics that the Shroud owns and that should be present in the image produced by at least one of the two experiments or both.

Now, also accepting the results already obtained, we ask ourselves:

1. How would it be possible for the above identified photochemical processes (Di Lazzaro et al., 2012) to yellow only and only the right fibrils leaving the background color to the others?

2. Is it certain that the yellowed fibrils (the ones that will yield the body image) will all have the same optical density?

3. Will be the yellow fibrils distribution of the obtained body image able to furnish an I(z) correlation, between the density of the above fibrils and the body-sheet distance (Fazio et al., 2019; Jackson et al., 1982 and 1984), represented by a linear regression?

4. Could the possible presence of balms and perfumes (Pellicori, 1980; Curciarello et al., 2012; Boi, 2017 and 2020) modify the Shroud-like color? 
5. Is it certain that the resolution of the obtained image will be about $5 \mathrm{~mm}$ ? The function $\mathrm{I}(\mathrm{z})$, extracted from the distribution in the $(\mathrm{I}, \mathrm{z})$-plane appears many scattered. In fact, the correlation coefficient squared is $r^{2}=0.60$. However, the linear function is the best fit possible (Jackson et al., 1982 and 1984). Not accepting the above function is like admitting that there is no correlation between the density of yellowed fibrils (or intensity of image) and the body-sheet distance. This would be inadmissible. In our opinion, we should find the motivation that have yielded these anomalies. Here, it is necessary to remember that the idea of this trend starts from afar: Vignon (1902, 1902a, 1937 and 1938) and Delage (1902).

Recently, we investigated problems that involved the Transcendent and the Immanent (Fazio, 2020 and 2021). For us, these two areas of investigation are separate. However, we want to underline a difference between the above areas: while the events of the Immanent remain confined in your area, the ones of the Transcendent, istantly left a trace in the rational world. This must be so because the transcendental events have origin in their area but they are addressed to the Immanent area. In fact, to the natural science it is permitted to understand if such an event it is occurred without being able to say anything else.

In the two cases of our concern, the start of the two experiments is due to a transcendental event (the presence of a corpse that emits ultraviolet radiation) that goes on, in the Immanent, respecting the laws of the natural sciences. In our opinion, this occurs because some scientists wish to demonstrate that the Shroud body image formation is the result of a supernatural event. They don't take into account that the Miracle happens instantly (Fazio, 2020). Therefore, such an event occurs with infinite speed and for this reason it is and will always be incomprehensible for the physics, chemistry and other natural sciences. However, we agree with Fanti (2010) and Di Lazzaro et al. (2012) on the man of the Shroud: He is Jesus Christ of the New Testament, the Nazarene (Fazio, 2021).

The procedure that they have adopted to find the above formation mechanism, in its complexity, is not corrected. The beginning occurs irradiating a linen with electromagnetic radiation in the zone of the far ultraviolet, a non-natural event. Afterwards, they continue with natural procedure in the attempt to obtain a body image as close as possible to the Shroud one. This means that the man wrapped in the burial linen, il Nazarene, at a certain instant has emitted UV radiation of high energy (photons). That is, it is like if we understood a supernatural event, that occurs in a time $\mathrm{t}=0$, describing it step by step.

\section{CONCLUSION}

We investigated two processes, in part realized, whose authors had and have in mind to reproduce a body image as it is on the Shroud of Turin. These two processes use both the UV radiation. In the first case, by Corona Discharge, it is yielded heat and UV radiation; in the second case, by pulsed excimer laser (ArF), it is possible to work in the far UV. For the authors, of the above lines of research, the use of ultraviolet radiation it is necessary to reach the result.

Differently of the above conviction, we remember that there are other scientists (Rogers and Arnoldi, 2002; Rogers, 2004 and 2005) certain that a corrected use of the Scientific Method applied to the Shroud of Turin does not agree with the choice of UV radiation. Also Schwortz (2021) affirms: "I principally believe there are properties of the image that radiation cannot account for. I tend to favor chemical reaction." Therefore, together with us, there are the other scholars that ask to discard the radiative hypotheses. 
However, we reiterate that in the first century AD sepulcher there is only one available source of energy. It is the corpse wrapped in the burial linen that emits, with weak intensity, thermal energy. In our opinion, there are not other sources that the natural sciences could accept. Moreover, the existence of a correlation between the density of yellowed fibrils (or image intensity) and the body-sheet distance points towards a natural explanation rather than a transcendental one.

What we say is supported by the "Ockham's razor" which is not a physical law but a philosophical razor used to eliminate improbable options: "Among competing hypothesis, the one with the fewest assumption should be selected." (Soklakov, 2003). However, the above razor, starting with Newton, it has been appreciate by many scientists. This idea goes back at least as far as Aristotle, who wrote: "Nature operates in the shortest way possible."

It is clearly evident, that investigating the Turin Shroud is very difficult for everyone. However, many scientific problems, sometimes with difficulty, have been resolved. Therefore, it is necessary to continue. Unfortunately, nowadays there are authoritative Shroud researchers that in their works involved the Creed, the spirituality and the emotionality. Differently, to study correctly the above archeological finding, the scientists must have as reference the laws of the natural sciences and apply the Scientific Method, as it happens for all the areas of research.

ACHNOWLEDGEMENTS: The Author thanks the Eng. Francesco Fazio for the help along the revision of the English text.

\section{BIBLIOGRAPHY:}

[1] Antonacci, Mark. The Resurrection of the Shroud. M. Evans \& Co., Inc, New York. 2000.

[2] Antonacci, Mark. 2012. "Particle radiation from the body could explain the Shroud's images and its carbon dating", in Scientific Research and Essay, 7(29): 2613-2626.

[3] Boi, Marzia. 2017. "Pollen on the Shroud of Turin: The Probable Trace Left by Anointing and Embalming", in Archaeometry, 59: 316-330.

[4] Boi, Marzia. 2020. "The Traces left on the Shroud by Anointing and Embalming”, in Sindon, 0: 26-30.

[5] Curciarello, Francesca, Veronica De Leo, Giovanni Fazio and Giuseppe Mandaglio. 2012. "The abrupt changes $8 \mathrm{n}$ the yellowed fibril density in the Linen of Turin", in Radiation Effects and Defects in Solids, 167: 224-228.

[6] Delage, Yves. 1902. "Le Linceul de Turin. Lettre à M.C. Richet”, in La Revue Scientifique, 22: 683-687.

[7] Di Lazzaro, Paolo, Daniele Murra, Antonio Santoni, Enrico Nichelatti and Giuseppe Baldacchini. 2012. "Superficial and Shroud-like coloration of the linen by short laser pulses in the vacuum ultraviolet", in ,Applied Optics, 51: 8567-8578.

[8] Fanti, Giulio. 2010. "Can Corona Discharge explain the body image of the Turin Shroud", in Journal of Imaging Science and Technology, 54: 20508-1-11.

[9] Fazio, Giovanni and Giuseppe Mandaglio. 2011. "Stochastic distribution of the fibrils that yielded the Shroud of Turin body image", in Radiation Effects and Defects in Solidis, 166: 476-479.

[10] Fazio, Giovanni and Giuseppe Mandaglio. 2012. "Can a latent image explain the characteristics of the Shroud body image?", in Radiation Effect and Defects in Solids, 167: 220-223.

[11] Fazio, Giovanni, Veronica De Leo, Francesca Curciarello and Giuseppe Mandaglio. 2015. "Comparison among the Shroud body image formation mechanisms by the linen fibrils distributions", in The Journal of The Textile Institute, 106: 896-899

[12] Fazio, Giovanni, Giuseppe Mandaglio and Antonio Anastasi. 2019. "Describing, Step by Step, the Shroud Body Image Formation", in Heritage, 2: 34-38.

[13] Fazio, Giovanni. 2020. “The Shroud Body Image Generation. Immanent or Transcendent Action?", in Scientia et Fides, 8(1): 33-42.

[14] Fazio, G. 2021. "A Theological Support, from Chalcedon, to the Shroud Image Natural Formation", in International Journal of Theology, Philosophy and Science, 8: 42-48. 
[15] Feller, Robert I. Accelerated aging: photochemical and thermal aspects. Dinah Berland Editor, The J. Paul Getty Trust, USA. 1994.

[16] Gilbert, Roger Jr. and Marion M. Gilbert. 1980. "Ultraviolet-Visible Reflectance and Fluorescence Spectra of the Shroud of Turin", in Applied Optics 19: 1930-1936.

[17] Heller, John H. and Alan D. Adler (1981) 'A chemical investigation of the Shroud of Turin' Canadian Society of Forensic Sciences Journal 14: 81-103.

[18] Jackson, P. John, Eric J. Jumper and William R. Ercoline. 1982. "Three Dimensional Characteristic of the Shroud Image", in IEEE 1982 Proceeding of the International Conference on Cybernetic and Society, October 1982, pp. 576-579.

[19] Jackson, P. John, Eric J. Jumper and William R. Ercoline. 1984. "Correlation of Image Intensity on the Turin Shroud with the 3-D structure of a human body shape", in Applied Optics, 23: 2244-2270.

[20] Jumper, J. Eric, Alan D. Adler, John P. Jackson, Samuel F. Pellicori, John H. Heller and James R. Druzik. 1984. "A Comprehensive Examination of the Various Stains and Images on the Shroud of Turin", in ACS Advance in Chemistry. Archaeological Chemistry III, 205: 447-476.

[21] Pellicori, F. Samuel and Mark S. Evans. 1981. "The Shroud of Turin through the microscope", in Archaeology, 34: 34-43.

[22] Miller, D. Vernon and Samuel F. Pellicori. 1981. "Ultraviolet Fluorescence Photography of the Shroud of Turin", in Journal of Biological Photography, 49: 71-85.

[23] Mottern, W. Robert, Ronald J. London and Rogers A. Morris. 1980. "Radiographic Examination of the Shroud of Turin. A Preliminary Report", in Materials Evaluation, 38: 39-44.

[24] Pellicori, Samuel F. 1980. "Spectral Properties of the Shroud of Turin", in Applied Optics, 19: 19131920.

[25] Pellicori, F. Samuel and Mark S. Evans. 1981. "The Shroud of Turin through the microscope", in Archaeology, 34: 34-43.

[26] Rinaudo, Jean Baptiste. 1993. "Nuveau Mecanisme de Formation de 1'Image sur le Linceul de Turin, Ayant $\mathrm{Pu}$ Entrainer une Fausse Radiodatation Medievale", in Proceeding International Scientific Symposium, Rome pp. 293-299.

[27] Rinaudo, Jean Baptiste. 1994. "Proton Model”, in BSTS Newsletter 38: 13-16.

[28] Roger, N. Raymond and A.nna Arnoldi. 2002. "Scientific Method Applied to the Shroud of Turin. A Review", in http;//www.shroud.com/pdfs/rogers2.pdf pp. 1-38.

[29] Rogers, N. Raymond. 2004. "Frequently Asked Questions (FAQs)", in http://www.shroud.com/pdfs/rogers5faqs.pdf pp. 1-19.

[30] Rogers, N. Raymond. 2005. "The Shroud of Turin: Radiation effects, aging and image formation", in https://www.shroud.com/pdfs/rogers8.pgf pp. 1-10.

[31] Schwortz, M. Barrie. 2021. Personal communication.

[32] Schwalbe, A. Larry and Raymond N. Rogers. 1982. "Physics and Chemistry of the Shroud of Turin. A summary of the 1978 investigation", in Analytica Chimica Acta, 135: 3-39.

[33] Soklakov, N. Andrei. 2003. "Occam Razor as a formal basis for a physical theory", in Foundation of Physics Letters, 15(2): 107-135.

[34] United States Conference of Catholic Bishop. 2010. "The New American Bible, Revised Edition.”, in Confraternity of Christian Doctrine Inc. Washington DC.

[35] Vignon, Paul. 1902. "Le Linceul Du Christ. Etude Scientifique", in Libraires de l'Academie de Medecine. Masson et Cie Editeurs, Paris. Reprinted in 1970 by University Books, New Hyde Park, New York.

[36] Vignon, Paul 1902a. "Reponse à M. Vernes.”, in Revue Scientifique, 22: 623-628.

[37] Vignon, Paul and Edward A. Wuenshel. 1937. "The problem of the Holy Shroud", in Scientific American, 156: 162-164.

[38] Vignon, Paul. 1938. "La Saint Suaire de Turin devant la Science, l'Archeology, l'Histoire, l'Iconographie, la Logique", in Masson et Cie Editeurs, Paris. 